\title{
Ixodid ticks, fleas and lice infesting dogs and cats in Hawassa, southern Ethiopia
}

\author{
Authors: \\ Bersissa E. Kumsa ${ }^{1,2}$ \\ Shewit Mekonnen ${ }^{1}$ \\ Affiliations: \\ ${ }^{1}$ Department of Parasitology, \\ Addis Ababa University, \\ Ethiopia \\ ${ }^{2}$ Department of Experimental \\ Sciences, University of \\ Padova, Italy

\section{Correspondence to:} \\ Bersissa Kumsa \\ Email: \\ bersissak@yahoo.com

\section{Postal address:} \\ PO Box 34, Bishoftu, Ethiopia

\section{Dates:} \\ Received: 25 Feb. 2011 \\ Accepted: 19 Apr. 2011 \\ Published: 04 Oct. 2011 \\ How to cite this article: \\ Kumsa, B.E. \& Mekonnen, S. \\ 2011, 'Ixodid ticks, fleas and \\ lice infesting dogs and cats in \\ Hawassa, southern Ethiopia', \\ Onderstepoort Journal \\ of Veterinary Research \\ 78(1), Art. \#326, 4 pages. \\ doi:10.4102/ojvr.v78i1.326
}

(C) 2011. The Authors. Licensee: AOSIS OpenJournals. This work is licensed under the Creative Commons Attribution License.
This study investigated the prevalence, risk factors and species composition of ticks, fleas and lice infesting dogs and cats in and around Hawassa in southern Ethiopia. In total, 200 dogs and 100 cats were examined from November 2008 to April 2009. Of the dogs and cats examined, $99.5 \%$ and $91.5 \%$, respectively, were infested with one or more species of ticks, fleas or lice. The overall prevalence was higher in dogs than in cats. A total of six different species of ectoparasites were collected and identified from dogs, but only three species from cats. Ctenocephalides felis was the predominant species amongst the animals, with a prevalence of $82.9 \%$ on dogs and $67 \%$ on cats. Other prevalent species on dogs included Ctenocephalides canis (73.8\%), Heterodoxus spiniger (4\%), nymphs of Amblyomma spp. (3.5\%), Pulex irritans (2.5\%) and Haemaphysalis leachi $(0.5 \%)$. C. canis $(18 \%)$ and P. irritans $(6 \%)$ were also found on cats. More female than male fleas and lice were observed. The study revealed that the prevalence of fleas, ticks and lice on dogs was not significantly different between male and female animals or between young and adult dogs. However, the prevalence of these ectoparasites was significantly higher in female than in male and in adult than in young cats. The study showed that the prevalence of ectoparasites on both dogs and cats was significantly higher on animals with flea allergy dermatitis (FAD) than those without FAD, and on animals with lesions on their skin compared with those without lesions.

\section{Introduction}

Dogs and cats are the most commonly owned companion pets worldwide. For instance, in the USA $60 \%-70 \%$ of households own at least one companion animal (Moriello 2003). In Ethiopia, many families own dogs and cats. Dogs are kept for guarding, hunting or as pets, especially in larger towns, whilst cats are mainly kept for hunting house rodents. Despite the presence of a large population of dogs and cats in Ethiopia there is paucity of information regarding the number, breeds, management systems and health status of these animals (Yacob, Ataklty \& Kumsa 2008).

Ectoparasites are one of the major constraints to the health and performance of domestic animals worldwide. Ectoparasites are common on dogs and cats, presenting an important cause of pruritic as well as nonpruritic skin disorders. They transmit a variety of diseases and cause hypersensitivity. Ticks, fleas and lice are the predominant ectoparasites encountered on domestic dogs and cats in several countries around the world. Their feeding or movement patterns may have several direct and indirect effects on their hosts (Alcaino, Gorman \& Alcaino 2002; Rinaldi et al. 2007).

Common ixodid tick species that infest dogs and cats belong to the genera Amblyomma, Rhipicephalus and Haemaphysalis. Ticks cause direct damage owing to their blood-feeding behaviour, act as vectors for bacterial, rickettsial, viral and protozoal diseases and may also cause tick paralysis owing to poisonous injections (Marchiondo et al. 2007; Wall \& Shearer 1997). Many species of fleas have been recorded from different animal species. Echidinophaga gallinacea (the sticktight poultry flea), Pulex irritans (human flea), Leptosylla segnis (rat flea), and Ctenocephalides felis and Ctenocephalides canis are the most commonly reported species of fleas from dogs and cats. The infestation of an animal with fleas generally reflects poor management by the owners. The effects of flea bites include severe pruritus, self-inflicted trauma and flea allergy dermatitis (FAD), a specific skin disease of dogs and cats (Soulsby 1982). Fleas harboured by pets can serve as intermediate hosts for the nematode, Acanthocheilonema reconditum, and the dog tapeworm, Dipylidium caninum, both of which can parasitise humans (Soulsby 1982). Xenosylla cheopis is the chief vector of the human pathogen Yersinia pestis, causing human plague (Marchiondo et al. 2007; Wall \& Shearer 1997). In addition, fleas have been implicated in the transmission of the etiologic agent of cat-scratch zoonosis (Comer, Paddock \& Childs 2001).

Despite the large numbers of dogs and cats in Ethiopia, very few studies have been conducted on the ectoparasites of these animals. As a result there is paucity of information on the distribution, 
species composition, public awareness and zoonotic importance of ectoparasites of dogs and cats in Ethiopia (Melkamu 2008; Yonas 2008). Thus, the current study was aimed at determining the species composition and prevalence of ticks, lice and fleas on domestic dogs and cats in Hawassa in the southern parts of Ethiopia.

\section{Materials and methods Study area}

The study was conducted in Hawassa, which is capital of the Southern Nations and Nationalities Peoples Regional State (SNNPR), located $275 \mathrm{~km}$ south of Addis Ababa. Geographically the area lies between the latitudes $4^{\circ} 27^{\prime} \mathrm{N}$ and $8^{\circ} 30^{\prime} \mathrm{N}$ and between the longitudes $34^{\circ} 21^{\prime} \mathrm{E}$ and $39^{\circ} 1^{\prime} \mathrm{E}$. The annual mean temperature of the area is about $25^{\circ} \mathrm{C}$, whereas the annual mean rainfall varies from $801 \mathrm{~mm}$ to $1000 \mathrm{~mm}$.

\section{Study animals}

Ectoparasites were sampled during a house-to-house survey of dogs and cats in Hawassa and regular weekly visits to a veterinary clinic. The animals included in the study were randomly selected for examination.

\section{Study methodology}

A cross-sectional study was performed from November 2008 to April 2009 based on the house-to-house survey and regular examination of animals presenting at the Selassie Veterinary Clinic in Hawassa.

\section{Ectoparasite collection and identification}

Both dogs and cats were thoroughly examined for the presence of ectoparasites during regualar examinations lasting $10 \mathrm{~min}-15 \mathrm{~min}$ (Soulsby 1982). The host's skin was also brushed with a fine comb after being rubbed with a piece of cotton soaked in ether. The use of a plastic comb and white paper allowed for thorough examination for the presence of ectoparasites. Live ticks were removed from the animals manually by using forceps, whilst fleas and lice were brushed off the dogs' fur onto white sheets of paper using a brush and plastic comb. All collections were preserved in a solution of $70 \%$ ethanol and identified to species level under a stereomicroscope, according to the standard morphological identification keys as described by Soulsby (1982), Urquhart et al. (1996) and Walker et al. (2003). Clinical symptoms suggestive of FAD were mainly itching and associated lesions (e.g. erythema, crusted papules, excoriations, alopecia, scales, desquamation and hyperkeratosis) were assessed during physical examination of the animals (Durden et al. 2005; Koutinas et al. 1995; Rinaldi et al. 2007).

\section{Data analysis}

All collected data were entered into spreadsheets and analysed with statistical software (SPSS, version 15). Data were summarised as descriptive statistics (mean and percentages) and displayed as tables. The confidence level for the analyses was set at 95\%, with significance level assessed at $p<0.05$.

\section{Results}

As shown in Table 1, 199 of the examined dogs (99.5\%) were infested with one or more species of ectoparasites. C. felis was the most prevalent species $(82.9 \%)$, whereas C. canis was the second most common species (73.8\%). Nymphs of Amblyomma spp. were the most prevalent ticks on dogs, with a prevalence of $3.5 \%$, followed by Haemaphysalis leachi $(0.5 \%)$.

Of the total of 100 cats examined, 91 (91\%) were infested by one or more species of ectoparasites (Table 2). As for the dogs, C. felis was the most common species found on cats $(67 \%)$, followed by C. canis (18\%). No ticks were found on cats during this study.

The results showed that the overall prevalence of fleas, ticks and lice on dogs was not significantly different $(p>0.05)$ between male and female, or between young and adult dogs (Tables 3 and 4). However, the overall prevalence of these ectoparasites was significantly higher $(p<0.05)$ amongst female compare with male cats, and also amongst adult compared with young cats (Tables 3 and 4).

A total of 1542 ectoparasites were collected from dogs during this study. Species included C. felis (female = 803; male $=175), C$. canis $($ female $=303$; male $=84), P$. irritans (female $=19$; male $=4)$, Heterodoxus spiniger $($ nymphs $=13$; female $=78$; male $=25)$, nymphs of Amblyomma spp. $(n=19)$ and $H$. leachi (female $=4$; male $=5$ ). A total of 493 ectoparasites were collected from cats during the study period. Species included C. felis (female $=300$; male $=72$ ), C. canis $($ female $=83$; male $=20)$, and $P$. irritans (female $=15$; male $=3$ ). Amongst fleas and lice, the number of female individuals was higher than that of male individuals.

Results showed that, for both cats and dogs, the prevalence of ectoparasites was significantly higher $(p<0.05)$ on animals

TABLE 1: Overall prevalence of ectoparasites on examined dogs $(n=200)$ in Hawassa.

\begin{tabular}{lll}
\hline Ectoparasite species & Number of positive dogs & Prevalence (\%) \\
\hline Ambylomma spp. & 7 & 3.5 \\
Haemaphysalis leachi & 1 & 0.5 \\
Heterodoxus spiniger & 8 & 4.0 \\
Ctenocephalides felis & 165 & 82.9 \\
Ctenocephalides canis & 147 & 73.8 \\
Pulex irritans & 5 & 2.5 \\
\hline Total & 199 & $\mathbf{9 9 . 5}$ \\
\hline
\end{tabular}

TABLE 2: Overall prevalence of ectoparasites on examined cats $(n=100)$ in Hawassa.

\begin{tabular}{lll}
\hline Ectoparasite species & Number of positive cats & Prevalence (\%) \\
\hline Ambylomma spp. & 0 & 0.0 \\
Haemaphysalis leachi & 0 & 0.0 \\
Ctenocephalides felis & 67 & 67.0 \\
Ctenocephalides canis & 18 & 18.0 \\
Pulex irritans & 6 & 6.0 \\
\hline Total & $\mathbf{9 1}$ & $\mathbf{9 1 . 0}$ \\
\hline
\end{tabular}


TABLE 3: Comparison of the overall prevalence of ectoparasites on male and female study animals.

\begin{tabular}{|c|c|c|c|c|c|}
\hline Animal & Sex & Number examined & Number of positive cases & Prevalence (\%) & $p$-value \\
\hline \multirow[t]{2}{*}{ Dog } & Male & 179 & 179 & 100 & - \\
\hline & Female & 21 & 20 & 99.5 & - \\
\hline Total & - & 200 & 199 & - & $p>0.05$ \\
\hline \multirow[t]{2}{*}{ Cat } & Male & 39 & 36 & 36 & - \\
\hline & Female & 61 & 55 & 55 & - \\
\hline Total & - & 100 & 91 & 91 & $p<0.05$ \\
\hline
\end{tabular}

TABLE 4: Comparison of the overall prevalence of ectoparasites on young and adult study animals.

\begin{tabular}{|c|c|c|c|c|c|}
\hline Animal & Age & Number examined & Number of positive cases & Prevalence (\%) & $p$-value \\
\hline \multirow[t]{2}{*}{ Dog } & Young & 32 & 31 & 96.9 & - \\
\hline & Adult & 168 & 168 & 100.0 & - \\
\hline Total & - & 200 & 199 & 99.5 & $p>0.05$ \\
\hline \multirow[t]{2}{*}{ Cat } & Young & 40 & 31 & 77.5 & - \\
\hline & Adult & 60 & 60 & 100.0 & - \\
\hline Total & - & 100 & 91 & 91.0 & $p<0.05$ \\
\hline
\end{tabular}

presenting with FAD than on those without FAD (Table 5). The prevalence of ectoparasites was significantly higher on animals with skin lesions than on those without lesions (Table 6).

\section{Discussion}

In this study a very high overall prevalence of ectoparasites was recorded amongst both dogs (99.5\%) and cats (91\%) in Hawassa. This prevalence suggests that these ectoparasites are very common and present major problems with regard to the health, use and performances of these important animals in the study area. This observation supports findings from Debre Zeit (Yonas 2008) and from Nekempte in western Oromia in Ethiopia (Melkamu 2008). It also agrees with reports from elsewhere in the world (Alcaino et al. 2002; Aldemir 2007; Beck et al. 2006; Canón-Franco \& Pérez-Bedoya 2010; Rinaldi et al. 2007).

The higher prevalence of ectoparasites recorded on dogs $(99.5 \%)$ than on cats $(91 \%)$ in this study may reflect more efficient grooming behaviour of cats, as has been suggested by Eckstein and Hart (2000).

Ctenocephalides felis was identified as the most common ectoparasite amongst both animal groups. This finding is in line with earlier reports from Ethiopia (Melkamu 2008; Yonas 2008) as well as elsewhere in the world (Alcaino et al. 2002; Aldemir 2007; Beck et al. 2006; Canón-Franco \& PérezBedoya 2010; Gonzalez, Castro \& Gonzalez 2004; Gracia et al. 2008; Rinaldi et al. 2007). C. canis was identified as the second most common ectoparasite species amongst both host groups, which also agrees with the earlier mentioned reports. The current study was the first to examine the prevalence of ectoparasites amongst dogs and cats in Hawassa.

Studies from various parts of the world indicated that C. felis, $C$. canis and $P$. irritans are the most common flea species that infest dogs and cats, which are regarded as the primary hosts for these three parasitic species. It was reported that $C$. felis was the most dominant species on dogs in Chile (Alcaino et al. 2002), Georgia, USA (Durden et al. 2005), southern Italy
(Rinaldi et al. 2007), and several areas in Germany (Beck et al. 2006), Spain (Gracia et al. 2008) and Colombia (CanónFranco \& Pérez-Bedoya 2010). However, Aldemir (2007) and Xhaxhiu et al. (2009) reported that C. canis was the predominant species of ectoparasites on dogs.

Ctenocephalides felis was the most prevalent species amongst domestic cats examined in this study, which agrees with the findings reported by Beck et al. (2006) in several areas of Germany and Xhaxhiu et al. (2009) in Albania. Another species of flea collected from the study animals was $P$. irritans (2.5\% and $6 \%$ from dogs and cats, respectively), which is in line with findings by Koutinas et al. (1995), Alcaino et al. (2002), Durden et al. (2005), Gracia et al. (2008) and CanónFranco and Pérez-Bedoya (2010). Yonas (2008) also reported C. felis as the most dominant ectoparasite species on dogs and cats in central Oromia, Ethiopia, followed by C. canis.

Nymphs of Amblyomma spp. represented the most prevalent tick species on dogs (3.5\%), followed by H. leachi (0.5\%). No ticks were recovered from cats during sample collection.

The prevalence of $H$. spiniger was $4 \%$, which is lower than what was previously reported by Yonas (2008) in Debre Zeit. This may be attributed to several factors, for example, variations in agroecology, time of study and animal management in various study areas.

A significant difference $(p<0.05)$ was observed in the prevalence of ectoparasite infestation between young and adult cats (Table 4), which may be due to young cats being confined to houses and therefore having greater exposure to ectoparasites infestation like fleas, as well as less efficient grooming behaviour than adult cats (Eckstein \& Hart 2000).

Similar to most other studies of ectoparasite prevalence amongst animals, more female than male fleas and lice were found on animals in this study. The most probable reason for this is that female individuals usually have a longer lifespan than the male individuals. Male individuals also spend more time off the host and are therefore more prone to predation or starvation than female individuals (Durden et al. 2005). 
TABLE 5: Overall prevalence of ectoparasites on dogs and cats with and without flea allergy dermatitis.

\begin{tabular}{|c|c|c|c|c|}
\hline Animal & Flea allergy dermatitis & Number infested & Prevalence (\%) & $p$-value \\
\hline \multirow[t]{2}{*}{ Dog } & Absent & 76 & 38.2 & - \\
\hline & Present & 123 & 61.8 & - \\
\hline Total & - & 199 & 99.5 & $p<0.05$ \\
\hline \multirow[t]{2}{*}{ Cat } & Absent & 34 & 37.4 & - \\
\hline & Present & 57 & 62.6 & - \\
\hline Total & - & 91 & 91.0 & $p<0.05$ \\
\hline
\end{tabular}

TABLE 6: Association between overall prevalence of ectoparasites and skin lesions amongst animals.

\begin{tabular}{|c|c|c|c|c|}
\hline Animal & Lesion & Number infested & Prevalence (\%) & $p$-value \\
\hline \multirow[t]{2}{*}{ Dog } & Yes & 152 & 76.0 & - \\
\hline & No & 47 & 23.6 & - \\
\hline Total & - & 199 & 99.5 & $p<0.05$ \\
\hline \multirow[t]{2}{*}{ Cat } & Yes & 80 & 87.9 & - \\
\hline & No & 11 & 12.1 & - \\
\hline Total & - & 91 & 91.0 & $p<0.05$ \\
\hline
\end{tabular}

\section{Conclusion}

In view of the findings it is possible to conclude that different species of fleas, ticks and lice represent common health and welfare problems of dogs and cats in Hawassa. Further studies regarding the role of these ectoparasites in transmission of diseases to dogs and cats, zoonotic importance, comparative prevalence and load, and the importance of dogs and cats as alternative hosts in different agroecology, urban and rural areas in Ethiopia are recommended so as to design an applicable control programme in the country.

\section{References}

Alcaino, H.A., Gorman, T.R. \& Alcaino, R., 2002, 'Flea species from dogs in three cities of Chile', Veterinary Parasitology 105, 261-265. doi:10.1016/S03044017(01)00626-4

Aldemir, O.S., 2007, 'Epidemiological study of ectoparasites in dogs from Eruzurum region in Turkey', Revue de Medecine Veterinaire 158(03), 148-151.

Beck, W., Boch, K.K., Mackensen, H., Wiegand, B. \& Pfister, K., 2006, 'Qualitative and quantitative observations on the flea population dynamics of dogs and cats in several areas of Germany', Veterinary Parasitology 137, 130-136. doi:10.1016/j. vetpar.2005.12.021, PMid:16442233

Canón-Franco, W.A. \& Pérez-Bedoya, J.L., 2010, 'Siphonaptera (Pulicidae) in dogs and cats of Colombia: Clinical and epidemiological aspects', Veterinary Parasitology 173, 353-357. doi:10.1016/j.vetpar.2010.07.014, PMid:20728994

Comer, J.A., Paddock, C.D. \& Childs, J.E., 2001, 'Urban zoonoses caused by Bartonella, Coxiella, Ehrlichia and Rickettsia species', Vector Borne Zoonotic Diseases 1 , Coxiella, Ehrlichia and Rickettsia species', Vector Borne Zoond
91-118. doi:10.1089/153036601316977714, PMid:12653141

Durden, L., Judy, T.N., Martin, J.E. \& Spedding, L.S., 2005, 'Fleas parasitizing domestic dogs in Georgia, USA: Species composition and seasonal abundance', Veterinary Parasitology 130, 157-162. doi:10.1016/j.vetpar.2005.03.016, PMid:15893082

Eckstein, R.A. \& Hart, B.L., 2000, 'Grooming and control of fleas in cats', Applied Animal Behavior Science 68, 141-150. doi:10.1016/S0168-1591(00)00095-2, doi:10.1016/S0168-1591(00)00094-0
Gonzalez, A., Castro, D. del C. \& Gonzalez, S., 2004, 'Ectoparasitic species from Canis familiaris (Linné) in Buenos Aires Province, Argentina', Veterinary Parasitology 120, 123-129. doi:10.1016/j.vetpar.2003.12.001, PMid:15019149

Gracia, M.J., Calvete, C., Estrada, R., Castillo, J.A., Peribanez, M.A. \& Lucientes, J., 2008, 'Fleas parasitizing domestic dogs in Spain', Veterinary Parasitology 151, 312-319. doi:10.1016/j.vetpar.2007.10.006, PMid:18031934

Koutinas, A.F., Papazahariadou, M.G., Rallis, T.S., Tzivara, N.H. \& Himonas, C.A., 1995, 'Flea species from dogs and cats in northern Greece: Environmental and clinical implications', Veterinary Parasitology 58, 109-105. doi:10.1016/03044017(94)00706-I

Marchiondo, A.A., Holdsworth, P.A., Green, P., Blagburn, B.L. \& Jacobs, D.E., 2007, 'World Association for the Advancement of Veterinary Parasitology (W.A.A.V.P.) guidelines for evaluating the efficacy of parasiticides for the treatment, prevention and control of flea and tick infestation on dogs and cats', Veterinary Parasitology 145, 332-344. doi:10.1016/j.vetpar.2006.10.028, PMid:17140735

Melkamu, T., 2008, 'Study on the ixodid ticks, fleas and lice of dogs and cats in Nekempte town, western Ethiopia', DVM thesis, Faculty of Veterinary Medicine, Addis Ababa University.

Moriello, K.A., 2003, 'Zoonotic skin diseases of dogs and cats', Animal Health Research Reviews 4, 157-168. doi:10.1079/AHR200355, PMid:15134297

Rinaldi, L., Spera, G., Musella, V., Carbone, S., Veneziano, V., lori, A. et al., 2007, 'A survey of fleas on dogs in southern Italy', Veterinary Parasitology 121, 69-70.

Soulsby, E.J.L., 1982, Helminths, Arthropods and Protozoans of Domesticated Animals, 7th edn., Baillienmire Jindan, London.

Urquhart, G.M., Armour, J.A., Duncan, J.L., Dunn, A.M. \& Jennings, F.W., 1996, Veterinary parasitology, 2nd edn., Blackwell Science, Oxford.

Walker, A.R., Bouattour, A., Camicas, J.L., Estrada-Peña, A., Horak, I.G., Latif, A.A. et al., 2003, Ticks of domestic animals in Africa: A guide to identification of species, Bioscience report, Edinburgh.

Wall, R. \& Shearer, D., 1997, Veterinary Entomology, 1st edn., Chapman and Hall, London.

Xhaxhiu, D., Kusi, I., Rapti, D., Visser, M., Knaus, M., Lindner, T. et al., 2009, 'Ectoparasites of dogs and cats in Albania', Parasitology Research 105, 15771587. doi:10.1007/s00436-009-1591-x, PMid:19690887

Yacob, H.T., Ataklty, H. \& Kumsa, B., 2008, 'Major ectoparasites of cattle in and around Mekelle, northern Ethiopia', Entomological Research 38, 26-30. doi:10.1111/ j.1748-5967.2008.00148.x

Yonas, A., 2008, 'Study on the ectoparasites of dogs and cats in Debre Zeit town, central Ethiopia', DVM thesis, Faculty of Veterinary Medicine, Hawassa University. 